\title{
E-Learning Readiness among Academic Staff in the Department of Information Science at the University of South Africa
}

\author{
Siphamandla Ncube \\ Department of Information Science, University of South Africa \\ Email: ncubels@unisa.ac.za \\ Luyanda Dube \\ Department of Information Science, University of South Africa \\ Email: dubel@unisa.ac.za \\ Patrick Ngulube \\ Email:ngulup@unisa.ac.za
}

Department of Interdisciplinary Research of the College of Graduate Studies, University of South Africa

Doi:10.5901/mjss.2014.v5n16p357

\begin{abstract}
An electronic (e-learning) readiness assessment identifying pertinent issues to be considered before and during an e-learning intervention is critical to the implementation of such an initiative. There is evidence that the introduction of a new innovation or even the upgrading of an existing one, is likely to be resisted, as people are sometimes attached to established pedagogies and practices. Although it is well documented that e-learning can assist the university to advance academic tution goals, it is important to note that these goals may be influenced by the lecturers' attitudes and behavioural intentions towards e-learning, hence, the need to check these perceptions and attitudes towards accepting technology as an teaching and learning innovation. In view of the envisaged deployment of e-learning at UNISA, the study adopted a qualitative approach to ascertain the opinions and experiences of academics in the the Department of Information Science regarding the preparedness towards e-learning. The study employed a variety of data-gathering methods, including observation, in-depth interviews, and document analysis. Overall, lecturers in the Department of Information Science seem to appreciate the value of e-learning athough there are apprehensions related to the lack of clear understanding of the e-learning process and its inferences for the university and its constituents. The study recommends that the Department of Information Science seeks more enlightenment on the understanding, prerogatives and implications of e-learning in order to craft a strategic trajectory that will underpin and butress a meaningful development of e-learning. Similarly, e-learning training interventions should be informed by a skills audit that will map out the capabilities and gift zones of lecturers.
\end{abstract}

Keywords: e-learning, teaching and learning, Department of Information Science, Open Distance Learning and University of South Africa

\section{Introduction and Background}

Although the value of e-learning and the technological imperative (Bates \& Poole 2013:9-10) is recognised there is evidence that some electronic learning (e-learning) initiatives have failed because the institution and its constituencies were not ready for the e-learning experience (Aydın \& Tasci 2005, Borotis \& Poulymenakou 2004, Karmakar \& Wahid nd.). There is evidence that the introduction of a new innovation or even the upgrading of an existing one, is likely to be resisted, as people are sometimes attached to established pedagogies and practices (Watkins, Leigh \& Triner 2004). It is important that e-learning endeavours into university education systems should be informed by the results of an e-learning readiness assessment identifying pertinent issues (Ssemugabi \& de Villiers 2010, Watkins, Leigh \& Triner 2004, Yun 2008). The evaluation of e-readiness entails a complex, integrated, inclusive and continuous process of identifying underlying factors likely to impact negatively on the deployment of e-learning (Carry \& Willis 2000, Clegg, Konrad \& Tan 2000, Cooper 2009, Kaur \& Abas 2004, Lopez 2007). These factors may be imbedded in traditional pedagogical principles, institutional conventions, as well as personal and attitudinal attributes (Govindsamy 2002). E-learning readiness for lecturers as well as students has been scrutinised in a plethora of diverse studies in the world over, and this study is an addition to that assemblage. 
The $21^{\text {st }}$ century is characterised by the technological imperative that has resulted in the universal deployment of elearning in higher education. This growing trend towards the use of e-learning is fuelled by emerging political, economic, technological and social developments brought about by globalisation, connectivity and competitiveness (Dyson 2004, Elearning methodologies 2011, Engelbrecht 2003, Higgins n.d., Smith \& Zenios 2004). The new developments have resulted in a competitive and volatile global landscape that requires universities to adopt technologies that will increase the employability of students.

E-learning is a global phenomenon that has no universal definition. Barake (2007) in Marimo, Mashingaidze \& Nyoni (2013) argues that the boundaries of e-learning are porous as a result there is still a lack of consensus about what e-learning is. Several authors state that the term e-learning refers to using web-based multimedia technologies to deliver support and enhance teaching and learning (Curran 2004, Engelbrecht 2003, Lopez 2007, Naidu 2006). In the same vein, Proffitt (2008) states that e-learning is an omnipresent process of teaching and learning where distance and time factors are bridged, and learning is convenient, easily accessible, reliable, flexible, and affordable. This article adopts the definition that e-learning entails the electronic delivery of instructional content or learning experiences that embodies a reconstruction of the educational agenda from a closed environment to one where there is open remote exchanges and collaboration between learners and peers as well as the educators (Carry \& Willis 2000, Clegg, Konrad \& Tan 2000, Cooper 2009, De Villiers 2005, Govindsamy 2002, Kaur \& Abas 2004, Proffitt 2008, Rajoo \& Krishnan n.d., Schreurs, Sammour \& Ehlers nd., Selim 2005).

Notable, e-learning has multiple benefits. It offers opportunities for asynchronous training, it enhances just-in-time training (So \& Swatman 2006), it is not limited by space (Aydin \& Tasci 2005, Becker 1991, Carry \& Willis 2001, Clegg, Konrad \& Tan 2000, Cooper 2009, De Villiers 2005, Engelbrecht 2003, Granic, Glavinic \& Stankov 2004, Kaur \& Abas 2004, Marimo, Mashingaidze \& Nyoni 2013, Yun 2008), location, time, it reduces costs (Abu-Hassan-Assari 2005, Engelbrecht 2003), it fosters national and international networks (Karmakar \& Wahid nd.), it enhances flexible and student-centred learning (Abu-Hassan-Assari 2005, Berke \& Wiseman 2004), as well as offering flexibility and autonomy between lecturers and students (Aydin \& Tasci 2005, Becker 1991, Carry \& Willis 2001, Clegg, Konrad \& Tan 2000, Cooper 2009, De Villiers 2005, Engelbrecht 2003, Granic, Glavinic \& Stankov 2004, Kaur \& Abas 2004, Yun 2008).

E-learning can enhance global reach because it can be delivered anywhere in the world as long as the appropriate equipment and infrastructure are provided (Marimo, Mashingaidze \& Nyoni 2013), it is not limited by space, location and time (Becker 1991, Carry \& Willis 2001, Clegg, Konrad \& Tan 2000, Cooper 2009, De Villiers 2005, Engelbrecht 2003, Granic, Glavinic \& Stankov 2004, Kaur \& Abas 2004). Likewise it can enhance self-directed learning which embodies independence or autonomy in learning wherein learners have greater control over learning as they are expected to function on their own (Eslaminejad \& Nakhaee 2012). This is the reson why this innovation is lauded as being an effective method of learning for adults who have busy schedules or live in remote areas, and unable to attend an everyday traditional classrooms (Hall 2001). Further, e-learning has the capacity to enable the institution to deliver a responsive, up-to-date and seamless learning experience. Given that the real value of e-learning lies not in its ability to train just anyone, anytime, anywhere, but in the ability to train the right people to gain the right skills or knowledge at the right time (Govindsamy 2002), it is critical all stakeholders understand and embrace e-learning.

Given the preceding background, the problem to which this study seeks an answer is the level of readiness or preparedness of academic staff in the Department of Information Science at UNISA for the deployment of e-learning. UNISA is an open distance learning (ODL) institution serving students that are geographically dispersed all over the world. ODL is a multidimensional concept aimed at bridging the time, geographical, economic, social, educational, and communication distance between student and institution, student and academics, student and courseware, and student and peers (UNISA 2008). Given its ODL mandate, from 2013 UNISA adopted a hybrid model that embeds the use of print and electronic tools for teaching and learning to selected undergraduate and postgraduate programmes. The adoption of e-learning resonates well with with the institutional mandate that champions the placement of students as the main foci of the educational process. Further, it is seen as a lever to achieve social responsibility and social justice by removing barriers that may impede access to learning, flexibility of learning provision and student centeredness.

The Department of Information Science is one of the departments in the School of Arts which is under the ambit of the College of Human Sciences at UNISA. The Department offers undergraduate and postgraduate programmes in library and information science (LIS) including archives and records management. By its very temperament library and information science subject field has evolved over the years to be oriented towards technology, with opportunities to exploit the unique features of the electronic medium or technology (Bates \& Poole 2003). Because of the new trends and developments in field, it is important that LIS education adapts to enhance the relevance and responsiveness of academic offerings and to enhance the graduatness and employability of students. The study intends to identify lecturers' perceptions of and behavioural intentions and attitudes towards e-learning because as indicated by Yiong (2008) they are 
positioned to play an important role in a successful e-learning experience by influencing students, motivating them to accept e-learning.

\section{Statement of the Problem}

Although it is well documented that e-learning can assist a university to advance academic tution goals, it is important to note that e-learning initiatives fail to take effect because of resistance and scepticism towards a new innovation or even an upgraded one (Bates \& Poole 2003; Gandolfo 1998 in Proffitt 2008). Resistance to innovations has less to do with the innovation itself and more to do with people who might be "grieving" the loss of established traditions and methods and thus seeing technology as a threat to past traditions (Bates \& Poole 2003; Cooper 2009, De Villiers 2005, Dyson 2004, Engelbrecht 2003, Govindsamy 2002, Granic, Glavinic \& Stankov 2004, Kaur \& Abas 2004, Tubaishat, \& Lansari, $2010-$ 2011). Given that resistance is a natural phenomenon it is important it is important to understand and respect lecturers' attitudes, perceptions and behavioural intentions towards e-learning (Aydin and Tasci 2005, Borotis \& Poulymenakou 2004, Faheeg 2011; Higgins nd., Karmakar \& Wahid nd.; Proffitt 2008). The readiness of lecturers who are enablers in tuition cannot be overemphasised, as their role is fundamental to the adoption and use of new technologies and pedagogical methods (Marimo, Mashingaidze \& Nyoni 2013).

In essence, it is critical that lecturers are not only in the correct frame of mind but also have the requisite skills and knowledge that would render them competent in e-facilitation as well as content development and management (Faheeg 2011, Govindsamy 2002, Vollery \& Lord 2000 (Yiong 2008). Bates and Poole (2003) caution that one reason e-learning often fails is that teachers try to carry over predominant styles of the classroom to the new media, rather than developing new pedagogies that would maximise the use of the new technology. One of the compeling arguments for the assessment of lecturers readiness is that the implementation of e-learning requires high investment costs on the part of the institution (Eslaminejad \& Nakhaee 2012), therefore to ensure return on investment the deployment of the e-learning process should be framed within the context of institutional readiness and participant-based approach inclined to understanding individual attitudes, perceptions, thoughts and considerations toward using a new innovation (Govindsamy 2002, Surry \& Land 2000 in Proffitt 2008).

Given that e-learning predicates that the role of lecturers extends beyond content developers and managers, to include tuition which entails supporting students acting as a buffer between them and the content as well as the elearning technologies (Govindsamy 2002, Proffitt 2008), it important that their concerns should be recognized. Lecturers are supposed to ensure an optimum level of interactions and discussions with students to enhance the e-learning experience by influencing and motivating students to accept e-learning environment (Ndubisi 2004; Ndubisi \& Chukwunonso 2004; Selim 2005). According to Salmon (2000) and Abouchedid \& Eid (2004), lecturers' characteristics such as confidence, positive behaviours, facilitation, knowledge sharing and creativity could promote interactions and motivate students to learn in an e-learning environment.

It is therefore critical to determine beforehand whether an institution has strategic leadership, sound financial base, infrastructure, technological and pedagogical support and lecturer capability and readiness (Bowles 2004 in Schreurs, Sammour \& Ehlers nd.). Disregading the readiness of lecturers to implement e-learning might be dire, as it might negate or undermine not only e-learning deployment and uptake by students, but also the achievement of institutional goals and objectives (Aydın \& Tasci 2005, Borotis \& Poulymenakou 2004, Govindsamy 2002, Karmakar \& Wahid nd.; Kaur \& Abas 2004; Tubaishat, \& Lansari, 2010-2011). The notion of assessing the levels of preparedness is likely to highlight the barriers to the use of technology and lessen probable causes of e-learning deployment failure, by ensuring avoidance of risk or resistance.

\section{Purpose of the Study}

This study assesses the preparedness of the lecturers for the introduction of e-learning in the Department of Information Science at UNISA. In particular, this study assesses the perceptions and opinions of lecturers concerning their readiness to accept e-learning as the dominant learning paradigm in the Department of Information Science at UNISA.

The research questions of the study have been formulated as follows:

i) What are lecturers' perceptions of e-learning?

ii) What are the perceived benefits of e-learning?

iii) What is the level of readiness for academics including self-efficiency toward e-learning interfaces?

iv) How are lecturers executing and facilitating e-learning?

v) What are the factors that are likely to impact on the adoption and usability of e-learning? 


\section{Research Methodology}

The qualitative approach was adopted to ascertain the opinions and experiences of academics regarding their preparedness towards e-learning. The researchers used the case study design (whereby the Department of Information Science is a case chosen within the UNISA community). The study employed a variety of data-gathering methods, including observation, in-depth interviews, and document analysis. Eight out of fourteen academics participated. All 15 members of staff were initially targeted for interviews but only eight were interviewed, as others were committed. In addition to this, institutional documents and related literature were analysed. Furthermore, the researchers drew on their experiences and exposure as members of staff in the Department of Information Science and UNISA employees. The results of a study that employs a basic analytical and interpretive design are interpretative and descriptive as is the case with this research.

\section{Results and Discussions}

The study focused on academics in the Department of Information Science highlighting their perceptions, level of readiness, and perceived self-efficiency toward e-learning interfaces. It also identified factors that are likely to inhibit or enhance lecturers' execution and facilitation of e-tuition. The results are presented according to dominant themes.

\subsection{Meaning of e-learning}

To set the scene the participants were asked to define the term e-learning. As it has emergerd from the literature that elearning has no universal definition, its boundaries are porous (Barake 2007 in Marimo, Mashingaidze \& Nyoni 2013), it was important for the study to determine the how the participants understand the meaning of the term. Five participants acknowledged that e-learning relies heavily on digital technology or web technologies to enable teaching and learning to happen in a virtual environment, allowing students to work at their own pace from any geographic location. After collating the responses it emerged that in its totality e-learning includes tuition, content development and management, content delivery, assessment, interactive participation, constant monitoring, ability to detect at risk students. One participant indicated that "there is no institutional definition of e-learning culminating from the non-existence of an e-learning policy". Further, she expressed that she does not know the nature, scope and extent of e-learning at UNISA. This is an indeterminate state that would impact on the understanding of the notion of e-learning as well as the implications of the deployment process.

\subsection{Strategies for executing e-learning}

When asked whether e-learning differs from traditional teaching, most participants stated that the pedagogy is still the same, although the medium for executing tutition has is novel and interesting. This is in contrary to the assertion made by Bates and Poole (2003) that e-learning requires lecturers to develop new pedagogies that would maximise the use of the new technology. The perception held by most participants might be that e-learning deployment in the University means the reorientation or change of medium for tuion rather than the altering of the fundamentals of teaching. This is a concern that shows not only the lacuna in the understanding of e-learning but also on the implication and expectations of the new strategy.

Some participants indicated that e-learning means transitioning from traditional teaching mode to the modern elearning mode through utilising myUnisa. They stated that even before commiting to e-learning UNISA as an ODL institution adopted myUnisa to enhance blended teaching and learning. MyUnisa is a synchonomous web-based portal using Sakai that allows academics to develop and teach online courses and which provides online communication, assessment and management tools. At its inception, myUnisa was not meant to replace printed material but was meant to enhance tuition through a binary learning model that championed blended learning. Some participants indicated that it is not very clear whether the University agenda is changing in 2013 with more inclinnation towards minimising the hybrid learning method in favour of a single mode of learning which is "paper behind the glass" or e-learning. One participant indicated that from her understanding "the University is still championing the hybrid model of learning and thus emphasising optimal exploitation of the myUnisa platform".

Although, some lecturers have used myUnisa before and they were able to distil enjoyment from the paperless nature of the medium which also meant improvement in connectivity, interactivity with students and the just-in-time communication. Further, the exposure afforded them the opportunity to explore and experience e-learning. Because e- 
learning at UNISA is conducted through myUnisa there is a danger that lecturers might equate the self-directed experience with myUnisa as e-learning. It has come out in the literature that shifting from traditional teaching to e-learning is an involving process that requires a paradigm shift involving a change of attitude, mind set and work patterns (Schneiderheinze 2005). Therefore, even though some academics have had the experience of using myUnisa this might not translate into competency or readiness to implement the e-learning initiative.

\subsection{Perceived benefits of e-learning}

The reason for asking questions about the benefits of e-learning was to determine whether participants understood and appreciated the perceived value of e-learning. The study assumes that the perceived value or lack thereof may have a bearing upon the uptake of e-learning. The benefits of e-learning were delineate according to the different variables:

\subsubsection{Benefits for lecturers}

First, one participant indicated that the benefit of e-learning was that "lecturers do not need to be physically in their offices to attend to students' queries". Understandably, because of the omnipresent nature of e-learning, there is an expectation that lecturers can execute their tuition responsibilities anywhere and anytime. This confirms the assertion made earlier by various authors that e-learning is not limited by time, space and location (Becker 1991, Carry \& Willis 2001, Clegg, Konrad \& Tan 2000, Cooper 2009, De Villiers 2005, Engelbrecht 2003, Granic, Glavinic \& Stankov 2004, Kaur \& Abas 2004). Contrary to this, some academics stated UNISA has a ruling that inferred that lecturers have to be in their offices for eight hours, which are the official working hours in the institution. Despite omnipresent traits of e-learning that infer virtual execution of tuition the preceding notion was highlighted as a discrepancy that the institution will have to consider and maybe rectify. One participant stated that "realistically it might be difficult for UNISA to manage lecturers in virtual offices and the expense of connectivity for everyone beyond the campus perimeter might stretch its economies of scale a bit". Nonetheless, as the implementation phase of e-learning gains momentum it is hoped that clarity on the issue of meaning of virtual orientation will be provided.

Second, the issue of improving communication through connectivity embedded in networked technologies interactive came out strongly. Communication is critical in ODL teaching and learning. One respondent stated that "elearning will improve interaction with students, it will facilitate advanced preparation and posting, as well as enhance visibility through involvement in social networks". Since e-learning involves real-time interaction or connectivity (synchronous and asynchronous), it will enable students to readily have access to study material and to also get feedback swiftly. One respondent highlighted that "students can discuss their conceptualisation of academic tasks easily and share ideas at the same time". This prospective cross-pollination through networking will hopefully enrich academic discourse and enhance the quality of education. Another respondent mentioned that "some students have always been eager to learn using technology; therefore, the e-learning drive will satisfy that quest". Some participants indicated that the online interface will accommodate many practical activities in different formats. This means that with online tuition lecturers could enhance their creativity to make learning interesting by pushing the frontiers posed by traditional teaching and learning methods. Considering that UNISA students are part of the global village, the opportunity to be connected will extend their personal and professional frontiers through networking (Karmakar \& Wahid nd). However, drawing from the use of myUnisa one participant highlighted that "participation in myUnisa discussion forums has not been optimally utilised by students". The discussion forum is a web-based forum on myUnisa for conversations or dialogue between lecturers and students and among students.

Third, it also came through that e-learning will save time with regard to turnaround time for feedback on assignments. One participant indicated that "the online tuition delivery mode could eliminate challenges related to delays in the delivery of tutorial matter". UNISA relies on the South African postal services to send tutorial matter; and assignments between students and the University. The challenge for the University usually emerges when there are protests in the postal services sector. Because of such disruptions mail is not delivered timeously which forces the University to consider rescheduling submission dates to accommodate the disruptions.

Fourth, generally most participants saw the advantage of conducting formative and summative assessments online. Currently, assignment questions are part of the tutorial letter which is sent to students mostly by post, although it also available electronically. With the implementation of e-learning, assignment questions will be posted online, assignments will be submitted and marked online. 


\subsubsection{Benefits the Department of Information Science}

By its nature the Department focuses on teaching the dogmas of information science discipline. The discipline has extensively grown over the years due to globalisation and technological developments that drive the knowledge economy. The implementation of e-learning is likely to empower lecturers and students with skills to explore e-technologies which is fundamental in the profession. One participant indicated that "web-technologies have vast opportunities and capabilities that are critical to capacitate students to ensure that they participate actively in knowledge economy". Another participant mentioned that "given the fact that information production and dissemination is predominantly technology based, it is only fair that students are equipped with appropriate skills, knowledge and attitudes to render them effective in the work environment." This is an indication of the possibility for e-learning to enable the Department of Information Science to enhance graduatness, responsiveness and relevance.

\subsubsection{Benefits for students}

The results affirmed the flexibility component of e-learning. E-learning was seen by a few participants as a major benefit to the students who could learn and be supported conveniently anywhere and any time. This resonates with the ODL philosophy of bridging time and space. Notwithstanding the fact that the demographic attributes of the UNISA student base have changed drastically over the years, the virtual component of e-learning delivery will benefit most students who are working, who live in far-off areas, who have family responsibilities and who have to cope with other realities. Given that UNISA has a widely dispersed student base, one respondent alluded to the fact that "with e-learning students will generally save time and money because travelling, accommodation, and other related costs will be eliminated". Another participant stated that 'the possibility of engaging in learning through smartphones and personal computers is a positive dimension considering that previously, students were expected to attend discussion classes, tutorials, seminars, workshops and other activities". They were also expected to travel to examination centres that were prescribed by the University. Although it is not yet clear how online examination will be handled, the assumption is that they will also be based on the virtual principle.

Since e-learning involves real-time interaction or connectivity, it will enable students to readily have access to study material and to also get feedback swiftly. Likewise, students can discuss their conceptualisation of academic tasks easily and share ideas at the same time. This prospective cross-pollination will hopefully enrich academic discourse and enhance the quality of education. Interestingly, one participant mentioned that "some students have always been eager to learn using technology; therefore, the e-learning drive will satisfy that quest". Considering that UNISA students are part of the global village, the opportunity to be connected will extend their personal and professional frontiers.

\subsubsection{Benefits for UNISA}

The participants indicated benefits for the University that include the following:

First, the reduction of cost in terms of paper, as e-learning is paperless. There will be no need to print those multiple pages of tutorial letters for approximately 300000 students in 2012. This will also enhance the institutional drive towards going green. Whether the cost will be redirected to priorities pertinent to e-learning was unknown. Second, the reduction of cost in terms of postage services including the risk of postage delays as indicated earlier. These delays disrupt institutional scheduling processes and procedures. With e-learning, challenges of late delivery or loss of assignments will be minimised. Third, costs related to logistical arrangements of tutors and lecturers travelling to conduct discussion classes will be minimised. Fourth, it was indicated that the new drive might assist the University in widening access and expanding its student base by deploying e-learning as a tool to attract prospective students. Fifth, given that UNISA has had the monopoly of being the only ODL institution in South Africa, it needs to re-strategise and scale-up its systems to maintain its competitive advantage, as many other universities in the country are threatening the monopoly by offering more online courses. Last, e-learning was commended as a good initiative that would enable the University to improve its standard of education in terms of computer literacy and competency of both staff and students in accordance with international standards. In terms of the timing and relevance of e-learning implementation at Unisa it was highlighted in accordance with national and international trends that the timing of adopting e-learning is perfect and relevant.

\subsection{Self-efficiency (aptitude)}

Academics were required to reflect on their competencies against the dictates for executing e-learning. Answers were 
varied and somehow contradictory. One respondent said "she believed that the training received towards e-elearning, the institutional support, and own knowledge and skills would help develop confidence to practise online tuition". Another one said "despite attending a few training interventions it seems as though e-learning was a daunting exercise that would require one to engage with it before being confident about the aptitude to execute online tuition". One respondent expressed that "training interventions were provided without prior determination of skills levels". This is likely to be problematic because the skills levels of academics are likely to differ due to unique nature of academic competencies. Similarly, some participants indicated that the lack of a clear understanding of the nature and scope of e-learning makes it difficult for one to confirm the appropriateness of ones' skills set. With regard to the skills there were no distinctions noted based on racial, educational gender or age dynamics.

\subsection{Factors likely to impact on e-learning}

With regard to a question about factors likely to impact on e-learning the participants highlighted the following:

\subsubsection{Students}

The major concern that came through was the issue of accessibility of appropriate web-based technologies and infrastructure as well as basic skills critical for e-learning to some students. Although the demographic profile of Unisa students have changed over time, a few participants indicated that the majority of students "still do not have basic computer skills". Given that most African rural areas generally do not have the infrastructure (electricity, computers, or network points) necessary for networking and connectivity, it might be a challenge for students in these areas to access and participate in online learning tuition. Further, some academics recalled that previously, students complained about not receiving printed study material in time, even though the material could be accessed online. Although UNISA have regional offices in the nine provinces students still experienced challenges with regard to accessing online study material. This could be attributed to various reasons including but not limited to accessibility of regional offices, lack of computer skills, or the lack of own connectivity resources (hardware and software). As one participant indicated, "this is a serious cause for concern, as the University might lose students to other contact institutions". Notably, this brings some element of contradiction, as it was indicated earlier that e-learning could enable the institution to expand its student base. Perhaps one could deduce that the assertion of loss or gain with regard to students will depend on the management and execution of the new agenda and also on students' expectations, convictions and realities. Notwithstanding the UNISA computer scheme meant to assist students with buying laptops and ipads at reasonable prices, some participants were sceptical of whether the scheme would bring reprieve for economically challenged students.

\subsubsection{Lecturers}

Another concern was about e-learning skills and overall readiness of academics, which require a shift from traditional methods of teaching to innovative ones. Linked to this is the fact that, as technology is evolving fast, one has to keep abreast with all the developments. Whilst e-learning was seen by some as a new and interesting prospect that would require optimal use of the myUnisa platform, others raised negative connotations. Of concern for some was that technology might be intimidating, as it usually leaves little room for errors that could be inevitable especially when one is also going through the learning process. Linked to the preceding assertion was the feeling expressed by one participant that "computer activities take longer, as one spends more time trying to remember the steps and not knowing any shortcuts". There were nuances that specifically surfaced, namely, that myUnisa is not necessarily user friendly. The time likely to be expended on executing e-learning was raised as a source of apprehension, given competing priorities that are part of academic responsibilities. Overall, with regard to skills development it was recommended that training interventions should be customised according to the skills level of the individuals in a discipline.

\subsubsection{E-learning infrastructure}

A concern was also raised about the appropriateness of infrastructure devices and systems needed to support e-learning, including bandwidth capacity and technical support. Clearly, e-learning implementation and uptake will put a strain on technology systems, processes and resources. If these are not properly aligned with probable demands, the discrepancy might contravene the intended targets and outcomes. It is well documented that connectivity in Africa is negatively affected mostly by inapt bandwidth size that does not equate constantly increasing demands and expectations. If the 
institution has not made appropriate provisions to deal with these challenges, they may negate the new progressive agenda. This shows the need to improve University systems so that they are congruent with the new agenda.

\subsubsection{E-learning examinations}

With regard to examinations the participants were not clear whether an online examination mode will be applicable. One participant mentioned that "it would be interesting to see how the University will address ethical issues that are likely to come up with online examinations". A few participants were sceptical about the practicality of online examinations. They expressed concerns that the inherent challenges might threaten the credibility and integrity not only of the examination process but also of the quality of output. Thus, it is not clear how the process of online examinations will evolve, but concerns about security issues were illuminated.

\subsubsection{Preparedness of the institution}

There was registered apprehension about the level of readiness of the institution and its stakeholders. There was a feeling that the speed at which things were done might have negative effects on the project. The participants alluded to the fact that e-learning should be implemented slowly and carefully, based on feasibility studies, upfront analysis of students' realities and institutional capabilities (resources). This is in unison with assertions discussed earlier that the implementation and adoption of a new initiative is a process that is supposed to factor in internal and external considerations. It was not clear whether the institution is considering using blended strategies with a strong component of online tuition or it accords equal weighting to both electroninc and print-based learning resources.

\section{Conclusions and Recommendations}

The study set out to determine the perceived perceptions of lecturers regarding their understanding of e-learning and their self efficacy towards e-learnining interfaces. Overall, lecturers in the Department of Information Science seem to appreciate the value of e-learning athough there are apprehensions related to the lack of clear understanding of the elearning process and its inferences for the university and its constituents. For instance, lecturers were unable to infer their competencies to execute e-learning tuition because there is no clear definition or barometer which can be used to measure one's aptitude. Although there is appreciation for e-learning, there are concerns emanating from the indeterminate state of e-learning in the institution. For example there is no institutional definition of e-learning that will lead to a common understanding of the term. Further, there is a need to clarify the institutional agenda and inclination towards a dominant or equivalent teaching and learning mode (s). This is a critical anomaly that have to be earnestly considered for the e-learning initiative to be successfully implemented with positive outcomes.

Furthermore, although the benefits of e-learning are recognised there are concerns related to the aptitude of most students as well as the accessibility of e-learning technologies. Since the implementation of e-learning is still in its infancy it is hoped that the results of this study will lead to a better understanding of the predicament and position of academics by those who drive e-learning initiatives. This could enable them to provide appropriate strategic leadership, clear institutional e-learning goals and implications as well as customised support interventions for academics. The study recommends that the Department of Information Science seeks more enlightenment on the understanding, prerogatives and implications of e-learning in order to craft a strategic trajectory that will underpin and butress a meaningful development of e-learning. Similarly, e-learning training interventions should be informed by a skills audit that will map out the capabilities and gift zones of lecturers. Last but not least, the institution should consider developing a more clear strategy on e-learning that will lessen indeterminate state and apprehension about e-learning.

\section{References}

Abouchedid, K., \& Eid, G.M. (2004). E-learning challenges in the Arab world: Revelations from a case study profile. Quality Assurance in Education, 12(1), 15-27.

Abu-Hassan-Assari, MH. 2005. Adult learners and e-learning readiness: a case study. A paper presented at the European College Teaching \& Learning Conference, 13-17 June.

Agboola, AK. (nd.) Assessing the awareness and perceptions of academic staff in using e-learning tools for instructional delivery in a post-secondary institution: a case study. The Public Sector Innovation Journal 11(3):1-12.

Ahmed, GAW. 2008. Modelling students' intention to adopt e-learning: a case study from Egypt. EJISDC. 34(1):1-13.

Aydin, CH. \& Tasci, D. 2005. Measuring readiness for e-learning: reflections from an emerging country. Educational Technology \& 
Society 8(4):244-257.

Bates, AW. \& Poole, G. 2003. Effective teaching with technology in higher education: foundations for success. San Fransico: JosseyBass.

Becker, H. 1991. When powerful tools meet conventional beliefs and institutional constraints. The Computing Teacher 18(8):6-9.

Borotis, SA. \& Poulymenakou, A. 2004. E-Learning readiness components: key issues to consider before adopting e-learning interventions. Paper presented at the World Conference on E-Learning in Corporate 2004, Washington, DC, pp. $1622-1629$. Available: http://www.eltrun.gr/papers/eLReadiness_ELEARN2004.pdf

Buabeng-Andoh, C. 2012. Factors influencing teachers's adoption and integration of information communication technology into teaching: a review of literature. International Journal of Education and Development using Information and Communication Technology (IJEDICT 8(1): 136-155.

Carry, D., \& Willis, J. 2001. Technology and teacher education. Association for the Advancement of Computing in Education. Charlottesville, VA.

Clegg, S., Konrad, J. \& Tan, J. 2000. Preparing academic staff to use ICTs in support of student learning. The International Journal for Academic Development (5):138-148.

Cooper, HM. 2009. Research synthesis and meta-analysis: a step by step approach (Applied social research methods) $4^{\text {th }}$ edition. Thousand Oaks, CA: Sage.

Curran, C. 2004. Strategies for e-learning in universities. Research \& Occasional Paper Series: CSHE.7.04. Available: http://ishi.lib.berkeley.edu/cshe. (Accessed on 12 August 2012).

De Villiers, MR. 2005. E-Learning artefacts: are they based on learning theory? Alternation 12 (1b):345-371.

De Villiers, MR. 2007. An action research approach to the design, development and evaluation of an interactive e-learning tutorial in a cognitive domain. Journal of Information Technology Education 6:455-479.

Dyson, LE. 2004. Cultural issues in the adoption of information and communication technologies by indigenous Australians. Proceedings Cultural Attitudes Towards Communication and Technology, Murdoch University, Australia, 58-71.

E-learning methodologies: A guide for designing and developing e-learning courses. 2011. Food and Agriculture Organisation of the United Nations (FAO): Rome, Italy.

Engelbrecht, E. 2003. A look at e-learning models: investigating their value for developing an e-learning strategy. Progressio 25(2):3847.

Eslaminejad, T. \& Nakhaee, N. 2012. Self-directed learning readiness factors in physicians for implementing e-learning in the continuing medical education programs. E-Learning Engineering, On- Job Training Interactive Teaching. Available: http://www.intechopen.com/books/e-learning-engineering-on-job-training-and-interactive-teaching/selfdirected-learning-as-arequirement-for-e-learning. Accessed on 25 September 2012)

Faheeg, IA. 2011. EFL students' readiness for e-learning: factors influencing e-learners' acceptance of the Backboard TM in a Saudi University. JALT CALL Journal, 7(1): 19-42.

Govindsamy, T. 2002. Successful implementation of e-learning: pedagogical considerations. Internet and Higher Education, 4:287-299.

Granic, A. Glavinic, V. \& Stankov, S. 2004. Usability evaluation methods for web-based educational systems. Available: http://www.ui4all.gr/workshop2004/files/ui4all_proceedings/adjunct/evaluation/28.pdf. (Accessed on 23 October 2012).

Hall, B. (2001). E-Learning Guidebook. Six Steps to Implementing E-Learning. Available: http://www.brandonhall. com/public/forms/sixstepdb. Accessed on 25 September 2012)

Hall, B. \& Snider, A. 2000. Glossary: The hottest buzz word in the industry. Learning 44(4):85-104.

Higgins, A. (nd.) Creating a national e-learning strategy in the open learning environment: a New Zealand case study. An abridged version of the Report of the E-Learning Advisory Group entitled Highways and Pathways: exploring New Zealand e-learning opportunities. Available: http://www.col.org/pcf2/papers/higgins_1.pdf. (Accessed on 25 September 2012).

Karmakar, CK. \& Wahid, CMM. (nd.) Recommendations for Bangladesh towards e-learning readiness. Available: http://codewitz.info/papers/MMT 97-102 Karmakar Wahid\%20.pdf. (Accessed on 12 September 2012).

Kaur, K. \& Abas, ZW. 2004. An assessment of e-learning readiness at the Open University Malaysia. Proceedings of the International Conference of e-learning. University of Quebec at Montreal, Canada, 22-23 June 2004.

Lopes, CT. 2007. Evaluating e-learning readiness in a health sciences higher education institution. Available: http://www.carlalopes .com/pubs/lopes_IADIS_2007.pdf. (Accessed on 19 October 2012).

Marimo, ST., Mashingaidze, S. \& Nyoni, E. 2013. Faculty of Education Lecturers' and students' perceptions on the utilisation of elearning at Midlands State University in Zimbabwe. International Research Journal of Arts and Social Science, 2(4):91-98. Available: http://www.interesjournals.org/IRJASS.

Ndubisi, N.O. (2004). Factors influencing e-learning adoption intention: Examining the determinant structure of the decomposed theory of planned behaviour constructs. Paper presented at the HERDSA 2004 Conference. (Miri, Sarawak, July, 4-7 2004). Retrieved January 2, 2004, from http://www.herdsa.org.au/conference2004/Contributions/RPap ers/P057-jt.pdf.

Ndubisi, N.O., \& Chukwunonso, N.C. (2004). On-line learning adoption intention: Comparing the predictive power of two competing models. Paper presented at the HERDSA 2004 Conference (Miri, Sarawak, July, 4-7 2004). Retrieved January 2, 2004, from http://herdsa2004.curtin.edu.my/ Contributions/RPapers/P058-jt.pdf.

Proffitt, LN. 2008. A study of the influence of learner readiness on academic success and student perceptions of online learning. A dissertation presented in partial fulfilment of the requirements for the Degree of Doctor of Philosophy, Capella University.

Saekow, A. \& Samson, D. 2011. Assessing e-learning acceptance by university students in Thailand. International Journal of e- 
Education, e-Business, e-Management and e-Learning 1(2):126-131.

Salmon, G. (2000). E-moderating: The key to teaching and learning online. London: Kogan Page.

Schneiderheinze, DD. 2005. Model for e-learning curriculum: differences from traditional classroom curriculum models. Online Journal for Workforce Education and Development, 1(3): 1-21. http://opensiuc.lib.siu.edu/cgi/viewcontent. (Accessed on 21 July 2012).

Schreurs, J. Sammour, G. \& Ehlers, U. (nd.) E-learning readiness: analysis eHealth case study of e-learning readiness (ERA).

Selim, H.M. (2005). Critical success factors for e-learning acceptance: Confirmatory factor models. Computers and Education. Retrieved February 9, 2007, from http://mail.phy.bg.ac.yu/ marijam/milos/science7.pdf.

So, T. \& Swatman, MC. 2006. e-Learning readiness of Hong Kong teachers.

Ssemugabi, S. \& De Villiers, MR. 2010. Effectiveness of heuristic evaluation in usability evaluation of e-learning applications in higher education. School of Computing, University of South Africa. SACJ (45).

Tucker, DT. 2007. A concerns-based approach to the adoption of web-based learning management systems. A dissertation submitted to the Graduate Faculty of North Carolina State University in partial fulfilment of the requirements for the Degree of Doctor of Education, Raleigh, North Carolina.

Tubaishat, A. \& Lansari, A. 2010-2011. Are students ready to adopt e-learning? A preliminary e-readiness study of a gulf University in the Gulf Region. International Journal of Information and Communication Technology Research 1(5): Available: http://www.esjournals.org. (Accessed on 03 September 2012).

Volley, T.,\& Lord, D. 2000. Critical Success Factors in online Education. The International Journal of Educational Management, 14 (5): 216-223.

Watkins, R. Leigh, D. \& Triner, D. 2004. Assessing readiness for e-learning. Performance Improvement Quarterly 17(4):66-79.

Yiong, BLC. 2008 Acceptance of e-learning among distance learners: a Malaysian perspective. Proceedings Ascilite, Melbourne.

Yun, CCL. 2008. Effects of personal characteristics on learner online learning readiness. Proceedings of the EDU-COM, International Conference, Perth, Western Australia 19-20 November. Available at: http://ro.ecu.edu.au/ceducom/31. (Accessed on 30 July 2012). 